\title{
Clinical neurorestorative progress in Parkinson's disease
}

This article was published in the following Dove Press journal:

Journal of Neurorestoratology

30 June 2015

Number of times this article has been viewed

\author{
Lin Chen ${ }^{1,2}$ \\ Hongyun Huang ${ }^{3-5}$ \\ Wei-Ming Duan ${ }^{6}$ \\ Gengsheng $\mathrm{MaO}^{3}$ \\ 'Department of Neurosurgery, \\ Yuquan Hospital, Tsinghua University, \\ ${ }^{2}$ Department of Neurosurgery, \\ Medical Center, Tsinghua University, \\ ${ }^{3}$ Department of Neurosurgery, \\ General Hospital of Chinese \\ People's Armed Police Forces, \\ ${ }^{4}$ Center of Cell Research, Beijing \\ Rehabilitation Hospital of Capital \\ Medical University, ${ }^{5}$ Beijing Hongtianji \\ Neuroscience Academy, ${ }^{6}$ Department \\ of Anatomy, Capital Medical \\ University, Beijing, People's Republic \\ of China
}

\begin{abstract}
Parkinson's disease (PD) is one of the common neurodegenerative diseases. Besides the symptomatic therapies, the increasing numbers of neurorestorative therapies have shown the potential therapeutic value of reversing the neurodegenerative process and improving the patient's quality of life. Currrently available novel clinical neurorestorative strategies include pharmacological managements (glial cell-line derived neurotrophic factor, selegiline, recombinant human erythropoietin), neuromodulation intervention (deep brain stimulation, repetitive transcranial magnetic stimulation, transcranial direct current stimulation), tissue and cell transplantation (fetal ventral mesencephalic tissue, sympathetic neurons, carotid body cells, bone marrow stromal cells, retinal pigment epithelium cells), gene therapy, and neurorehabilitative therapy. Herein, we briefly review the progress in this field and describe the neurorestorative mechanisms of the above-mentioned therapies for PD.
\end{abstract}

Keywords: Parkinson's disease, clinical study, neurorestorative treatment, cell transplantation, neuromodulation

\section{Introduction}

Parkinson's disease (PD) is the second most common neurodegenerative disorder worldwide, with main symptoms of stiffness, slowing of movement, and postural instability. ${ }^{1}$ Dementia commonly occurs in the advanced stages of the disease, whereas depression is the most common psychiatric symptom. PD affects approximately seven million people globally and one million people in the USA. ${ }^{2}$ The prevalence of PD is about $0.3 \%$ in the whole population of industrialized countries. PD is more common in the elderly and prevalence rises from $1 \%$ in those $>60$ years of age to $4 \%$ in the population aged $>80$ years. $^{3}$

The main pathological characteristic of PD is cell death in the substantia nigra and, more specifically, the ventral (front) part of the pars compacta, affecting up to $70 \%$ of the cells by the time death occurs. ${ }^{4}$ The occurrence of Lewy bodies is a key pathological feature of PD. ${ }^{5}$

The main families of drugs useful for treating motor symptoms are levodopa (usually combined with a L-3,4-dihydroxyphenylalanine (DOPA) decarboxylase inhibitor or catechol-O-methyl transferase inhibitor), dopamine agonists, and monoamine oxidase-B inhibitors. ${ }^{6}$ Most patients with PD eventually need levodopa and later develop motor side effects. When medications are not enough to control symptoms, surgery and deep brain stimulation (DBS) can be of use. ${ }^{7}$ Several attempts have been made to stimulate the neurorestorative process for nigral and/or striatal dopaminergic 
system by using pharmacological factors, gene expression, exercise, neuromodulation, and cell therapies.

\section{Clinical neurorestorative progress Medicines}

Glial cell-line derived neurotrophic factor (GDNF), infused unilaterally into the putamen for 6 months, could exert significantly sustained bilateral benefits and improve the quality of life in patients with PD. ${ }^{8}$ Supplementation with antioxidants such as selegiline, which have been used as monotherapy in early PD or in combination with levodopa in more advanced disease, might prevent or reduce the rate of progression of PD. ${ }^{9}$ Recombinant human erythropoietin (rhEPO) had beneficial effects on nonmotor symptoms but not on motor function. Nonmotor symptoms, such as cardiovascular autonomic dysfunction and cognition, which were refractory to dopaminergic treatment, showed improvement after the administration of rhEPO. ${ }^{10}$

\section{Neuromodulation}

\section{Deep brain stimulation}

Deep brain stimulation is recommended for people who have PD with motor fluctuations and tremor inadequately controlled by medication and for those who are intolerant to medication. ${ }^{7}$ DBS was first used by implanting multiple electrodes into the subcortical structure for treating hyperkinesis, ${ }^{11}$ then into the thalamus to treat tremor due to advanced PD in 1987, and, from 1993 onward, into the subthalamic nucleus or the globus pallidus. ${ }^{12}$ Furthermore, another study showed that DBS significantly improved psychological conditions, including depression, somatization, fear, anxiety, and psychosis, factors included in the symptoms checklist (SCL)-90, of patients with PD. ${ }^{13}$ After DBS treatment, levodopa dose was reduced by about $54.5 \%$. In contrast, levodopa dose was increased by $20.5 \%$ in the 36 th month in the control group. ${ }^{14}$ Due to the poor survival of dopaminergic cells after transplantation, DBS might be combined with cell therapy to manage PD in the future. ${ }^{15}$ A multitarget strategy aimed at improving symptoms with different pathogenetic mechanisms might be a promising approach in the near future.

\section{Transcranial stimulation}

Repetitive transcranial magnetic stimulation (rTMS) and transcranial direct current stimulation (tDCS) are noninvasive cortical stimulation methods that can benefit patients with PD and other movement disorders. Koch et al ${ }^{16}$ reported that rTMS at $1 \mathrm{~Hz}$ could markedly reduce drug-induced dyskinesias, whereas 5-Hz rTMS induced a slight but not significant increase. However, a systematic review revealed that high-frequency rTMS showed effects on motor signs in PD, during assessment with the Unified PD Rating Scale (UPDRS), and that low-frequency rTMS had only limited effect. ${ }^{17}$ Combination of the two should be encouraged; some evidence showed that preconditioning 1-Hz rTMS over primary motor (M1) by anodal tDCS could improve hypokinetic gait in patients with PD. ${ }^{18}$ Combined with physical training ${ }^{19}$ or dance therapy, ${ }^{20}$ tDCS could improve gait and balance in patients with PD. An open-label study ${ }^{21}$ showed that high-frequency repetitive deep TMS (rDTMS) might be a safe treatment for PD motor symptoms. The researchers used H-coils, inducing deeper and wider magnetic fields, over 12 rDTMS sessions spanning a period of 4 weeks at excitatory $(10 \mathrm{~Hz})$ frequency over the M1 and bilateral prefrontal regions. ${ }^{21}$

\section{Magnetic resonance-guided \\ focused ultrasound surgery}

The neuromodulation potential of ultrasonography was first described by Fry et $\mathrm{al}^{22}$ in the 1950 s, and the work is still in a preliminary stage. The new technique of magnetic resonanceguided focused ultrasound surgery (MRgFUS) was first used for cancer treatment. ${ }^{23}$ The method is currently the subject of many experimental and clinical trials, and it appears to be particularly promising in the ablation of tissues located deep in the brain and signifies the beginning of interventional neurology and an alternative to neurosurgery. The procedure does not require anesthesia and avoids the creation of a burr hole. ${ }^{24}$ The safety and effectiveness of this method have been observed in parkinsonian and essential tremors. ${ }^{25}$ More data and long-term follow-up will be required to learn whether ablative lesioning via FUS will lead to better outcomes with lower risks.

\section{Neurorehabilitation}

Rehabilitation as a complementary neurorestorative strategy can help patients with PD to maintain their quality of life. A randomized controlled trial showed that home-based, individualized occupational therapy led to an improvement in self-perceived performance in daily activities. ${ }^{26}$ Moderate-to-strong evidence exists for task-specific benefits of targeted physical activity training on motor performance, postural stability, and balance. ${ }^{27}$ Rhythmic auditory stimulation as a neurorehabilitative strategy for gait training could improve gait velocity, stride length, and step cadence in patients with PD. ${ }^{28}$ Efficacy of a physical therapy in patients 
with PD was confirmed by a randomized controlled trial. ${ }^{29}$ Most recently, a 2-year follow-up study demonstrated that intensive exercise in the early stages of the disease might slow down the progression of motor decay and it might delay the need for increasing drug treatment. ${ }^{30}$ Today, exercise training is widely used for rehabilitation of patients with PD. The short-term benefits from physiotherapy in PD have been clearly known and there are no differences between the different types of physiotherapy interventions. ${ }^{31,32}$

\section{Tissue graft and cell therapy}

Backlund et $\mathrm{al}^{33}$ first reported the transplantation of autologous adrenal medullary tissue into the striatum in two patients with severe PD, which showed some beneficial effects. Cell or tissue transplantation can potentially restore neurosurgical functions in patients with PD. Since then, numerous cell or tissue replacement therapies have been developed and tested.

\section{Fetal ventral mesencephalic tissue}

Clinical use of fetal ventral mesencephalic tissue as a treatment to replace dopaminergic neurons in patients with PD was first done 30 years ago. Dopamine neurons were transplanted ectopically into the striatum. They could structurally compensate for lost cells, form synaptic contacts with host neurons, release dopamine, restore dopamine transmission, and positively moderate gradual improvements in motor function in patients with PD. ${ }^{34-37}$ More important evidence that is accumulating shows that L-3,4-dihydroxy-6-[18F]fluoro-phenylalanine ( ${ }^{18} \mathrm{~F}$-DOPA) uptake increased significantly in the grafted striatum during a decade of follow-up by positron emission tomography (PET) studies. ${ }^{34}$

Two major randomized, double-blind, sham surgery placebo-controlled trials with neural grafts in PD have been performed. ${ }^{38,39}$ Even these trials could not meet the primary endpoints, with $15 \%-50 \%$ graft-induced dyskinesias at the initial study stage; the outcome of each trial was different from each other. Freed et al's ${ }^{38}$ results were better than Olanow et al's. ${ }^{39}$ Younger patients ( $\leq 60$ years of age) revealed significant improvement in the transplantation group as compared with the sham-surgery group by assessment with UPDRS and Schwab-and-England score; ${ }^{38}$ furthermore, after following up for 2-4 years after surgery, the grafts were effective at reducing the PD motor symptoms. At 2 years, clinical improvement was almost twice the level observed at 1 year and this was sustained at 4 years. Likewise, the increase of ${ }^{18} \mathrm{~F}$-FDOPA uptake was evident at 2 years and 4 years, with significant clinical-PET correlations. ${ }^{40}$ This strongly suggests that this therapeutic strategy may need years to reach its full effect.

Another report showed similar results; two patients were followed up for 15 years and 18 years, respectively, after surgery. One patient gradually improved his motor performance over the first 4 years posttransplantation. The other patient showed this effect until 2 years later. Importantly, they could stop their dopaminergic medication around 5 years postgraft, and motor benefits were still constant at their last assessment. $^{41}$

\section{Other cell therapies}

Four patients with PD underwent transplantation with autologous sympathetic neurons in the unilateral intrastriatal zone and improved their performance status by reducing the time spent in the off phase. ${ }^{42}$ Thirteen patients with advanced PD underwent bilateral stereotactic implantation with carotid body cells into the striatum, and most of them showed functional improvement 6-12 months after transplantation. ${ }^{43}$ Bone marrow stromal cells (BMSCs) transplanted into sublateral ventricular zone by stereotactic surgery were safe, with no serious adverse events in seven patients with PD during 10-36 months of follow-up; ${ }^{44}$ in another study, eight PD and four PD-plus patients showed improvement after BMSC transplantation during a 12-month follow-up. ${ }^{45}$

Human retinal pigment epithelial (hRPE) cells were transplanted into the putamen and lateral ventricles in 17 patients with PD. Three months later, the majority of patients showed functional improvement $(82.4 \%$ effect in the contralateral site and $64.7 \%$ in the ipsilateral site). ${ }^{46}$ In another study, hRPEs were implanted into the postcommissural putamen in 12 patients with $\mathrm{PD}$; eleven patients showed improvement in the primary outcome measure 3 months after transplantation and showed a peak at 12 months, which then declined during the next 24 months. PET analysis showed a trend with increased dopamine release during the first 6 months ${ }^{47}$ Even spheramine as hRPE cell microcarrier showed some effects in patients with PD in a 1-year, open-label, single-center study; ${ }^{48}$ recently the result of its further application was negative in a double-blind, randomized, controlled trial. ${ }^{49}$

Hallett et $\mathrm{al}^{50}$ examined the expression of dopamine transporters in human fetal midbrain cellular transplants. They found that dopamine transporters were robustly expressed in transplanted dopamine neuron terminals in the reinnervated host putamen and caudate for at least 14 years postimplantation. The transplanted dopamine neurons showed a healthy and nonatrophied morphology at all time 
points. The vast majority of transplanted neurons remained consistently healthy, with clinical findings of maintenance of function for up to $15-18$ years in patients. ${ }^{50}$

\section{Gene therapy}

Nine gene therapy clinical trials for PD have been initiated and completed. ${ }^{51}$ The first gene therapy trial, using glutamic acid decarboxylase gene with the adeno-associated virus vector, was conducted by unilateral subthalamic injection in 12 patients with PD in 2007. The procedure was safe and well tolerated by advanced patients with PD who had significant improvements in motor UPDRS scores 3 months after gene therapy and persisted up to 12 months. ${ }^{52}$ In 2008 , low dose of the AAV-human aromatic L-amino acid decarboxylase (hAADC) vector was tested in five patients with moderate-to-advanced PD, who had a modest improvement with PET evidence of sustained gene expression. ${ }^{53}$ AAV serotype 2-neurturin (CERE-120) was delivered into the substantia nigraplus putamen in 12 patients with PD who had some functional improvements, ${ }^{54}$ and this method with long-term follow-up was still feasible and safe. ${ }^{55}$

\section{Discussion}

\section{Neurorestorative mechanisms of cell therapy for PD}

\section{Fetal midbrain tissue}

Fetal brain tissue containing dopamine neurons was transplanted into the striatum of a rat model of PD in 1979, showing good survival and axonal outgrowth and significantly improving motor abnormalities. ${ }^{56}$ Different intrastriatal transplantation techniques might affect the result; intrastriatal transplantation of partial (tissue pieces) suspension by a metal cannula could have a higher survival rate of dopamine neurons, a greater reduction in amphetamine-induced rotations (overcompensation), and more extensive fiber outgrowth. ${ }^{57}$

Adrenal chromaffin, carotid body cells, and retinal pigment epithelial cells

Transplants of chromaffin cells derived from adrenal medulla or carotid body cell aggregates were explored in the early $1980 \mathrm{~s} .{ }^{58} \mathrm{hRPE}$ cells attached to gelatin microcarriers (Spheramine) were unilaterally transplanted into the putamen and improved behavioral scores were observed in PD models, with PET confirmation. ${ }^{59}$

\section{Mesenchymal stromal cells}

BMSCs were transplanted into the striatum, and this improved abnormal rotational behavior in a rat model of PD. ${ }^{60}$
Hypoxia can promote BMSC proliferation, dopaminergic neuronal differentiation, and then restore some functions after intrastriatal transplantation. ${ }^{61}$ In addition, allogeneic $\mathrm{BMSC}^{62}$ or human amniotic fluid stromal cell transplantation ${ }^{63}$ could improve urodynamic pressure on voiding function in PD rats. Umbilical cord stromal cells could survive well after transplantation in a parkinsonian mode ${ }^{64}$ and partially restore functions, ${ }^{65,66}$ as well as possessing the potential to transform into immature or mature neuron-like cells. ${ }^{67}$ The intravenous route of cell therapy has been tried in models of $\mathrm{PD} ;{ }^{68}$ umbilical cord blood CD34+ cells delivered by intravenous injection could ameliorate biochemical and histological motor deficits in 1-methyl-4-phenyl-1,2,3,6-tetrahydropyridineinduced parkinsonian mice and the strategy was even superior to levodopa in terms of its effect. ${ }^{69}$

Neural stem/progenitor cells, embryonic glialrestricted precursor cells, or embryonic stem cells

Neural stem/progenitor cells or undifferentiated embryonic stem cells when transplanted into the striatum could differentiate into neurons or dopaminergic neurons $\mathrm{s}^{70}$ and restore some functions. ${ }^{71,72}$ Delayed transplantation of embryonic glial-restricted precursor cells by exposure to bone morphogenetic protein could restore tyrosine hydroxylase expression and promote behavioral recovery through rescuing, not preventing, pathological changes. ${ }^{73}$

\section{Olfactory ensheathing cells}

Olfactory ensheathing cells transplanted with ventral mesencephalic cells could get better functional neurorestoration in a rat model of $\mathrm{PD}^{74}$ through increase in transplanted neural stem cell survival and functions $\mathrm{s}^{75,76}$ or modulation of intrinsic apoptotic pathways in parkinsonian rats. ${ }^{77}$ Neural grafts combined with olfactory ensheathing cells can maintain the functional improvement in animals or patients with PD longer. ${ }^{75}$

\section{Potential mechanisms of neuromodulation for PD}

DBS in the subthalamic nucleus can significantly affect striatal dopaminergic metabolism and markedly reduce dopaminergic medication ${ }^{78}$ or consequently activate substantia nigra compacta neurons via inhibition of gammaaminobutyric acid-ergic substantia nigra reticulate neurons. ${ }^{79}$ A recent study showed that high-frequency stimulation in the subthalamic nucleus could induce widespread anatomofunctional rearrangements through downregulation of Adrb1 protein. ${ }^{80}$ 


\section{Neurorestorative mechanisms of neurorehabilitation for PD}

Al-Jarrah et al ${ }^{81}$ found that endurance exercise training could promote angiogenesis in a mouse model of $\mathrm{PD}$. In addition, they found this training could decrease the expression of brain damage markers in the striatum, ${ }^{82}$ possibly by decreasing the level of neuronal nitric oxide. ${ }^{83}$ Strong evidence showed that long-term aerobic exercise could help functional motor and limbic circuits' reorganization in a rat model of $\mathrm{PD}^{84}$ and that longer-duration vibration training could significantly increase the number of nigrostriatal dopaminergic neurons. ${ }^{85}$

\section{Conclusion}

Currently, effective approaches to relieve symptoms in patients with PD are available; however, when faced with this neurodegenerative disease, extreme pessimism and unrealistic expectations are not good for patients and their treatment. Ongoing cell-based comprehensive neurorestorative therapies have made significant progress in clinical practice. The community needs to conduct more research into each promising strategy and optimize the benefits from current progress for patients with PD.

\section{Acknowledgment}

We thank Ms Lu Zheng for preparing this manuscript.

\section{Disclosure}

The authors report no conflicts of interest in this work.

\section{References}

1. Jankovic J. Parkinson's disease: clinical features and diagnosis. J Neurol Neurosurg Psychiatr. 2008;79:368-376.

2. Yao SC, Hart AD, Terzella MJ. An evidence-based osteopathic approach to Parkinson disease. Osteopath Fam Phys. 2013;5:96-101.

3. de Lau LM, Breteler MM. Epidemiology of Parkinson's disease. Lancet Neurol. 2006;5:525-535.

4. Davie CA. A review of Parkinson's disease. Br Med Bull. 2008;86: 109-127.

5. Dickson DV. Neuropathology of movement disorders. In: Tolosa E, Jankovic JJ, editors. Parkinson's Disease and Movement Disorders. Hagerstown, MD: Lippincott Williams \& Wilkins; 2007:271-283.

6. National Collaborating Centre for Chronic Conditions (NCCCC). Parkinson's Disease: National Clinical Guideline for Diagnosis and Management in Primary and Secondary Care. London: Royal College of Physicians; 2006:59-100.

7. Bronstein JM, Tagliati M, Alterman RL, et al. Deep brain stimulation for Parkinson disease: an expert consensus and review of key issues. Arch Neurol. 2011;68:165.

8. Slevin JT, Gash DM, Smith CD, et al. Unilateral intraputamenal glial cell line-derived neurotrophic factor in patients with Parkinson disease: response to 1 year of treatment and 1 year of withdrawal. J Neurosurg. 2007;106:614-620.

9. Pålhagen S, Heinonen E, Hägglund J, et al; Swedish Parkinson Study Group. Selegiline slows the progression of the symptoms of Parkinson disease. Neurology. 2006;66:1200-1206.
10. Jang W, Park J, Shin KJ, et al. Safety and efficacy of recombinant human erythropoietin treatment of non-motor symptoms in Parkinson's disease. J Neurol Sci. 2014;337:47-54.

11. Bekhtereva NP, Grachev KV, Orlova AN, Iatsuk SL. Utilization of multiple electrodes implanted in the subcortical structure of the human brain for the treatment of hyperkinesis. Zh Nevropatol Psikhiatr Im S S Korsakova. 1963;63:3-8.

12. National Collaborating Centre for Chronic Conditions (NCCCC). Parkinson's Disease: National Clinical Guideline for Diagnosis and Management in Primary and Secondary Care. London: Royal College of Physicians; 2006:101-111.

13. Tao Y, Liang G. Effect of subthalamic nuclei electrical stimulation in the treatment of Parkinson's disease. Cell Biochem Biophys. 2015;71(1): 113-117.

14. Bril' EV, Tomskiı̌ AA, Gamaleia AA, et al. A comparative study of the efficacy of deep brain stimulation of the subthalamic nucleus and pharmacological treatment in advanced Parkinson's disease. Zh Nevrol Psikhiatr Im S S Korsakova. 2014;114:55-61.

15. Cordeiro KK, Cordeiro JG, Furlanetti LL, et al. Subthalamic nucleus lesion improves cell survival and functional recovery following dopaminergic cell transplantation in parkinsonianrats. Eur $J$ Neurosci. 2014;39:1474-1484

16. Koch G, Brusa L, Caltagirone C, et al. rTMS of supplementary motor area modulates therapy-induced dyskinesias in Parkinson disease. Neurology. 2005;65:623-625.

17. Elahi B, Elahi B, Chen R. Effect of transcranial magnetic stimulation on Parkinson motor function - systematic review of controlled clinical trials. Mov Disord. 2009;24:357-363.

18. von Papen M, Fisse M, Sarfeld AS, Fink GR, Nowak DA. The effects of $1 \mathrm{~Hz}$ rTMS preconditioned by tDCS on gait kinematics in Parkinson's disease. J Neural Transm. 2014;121:743-754.

19. Kaski D, Dominguez R, Allum J, Islam A, Bronstein A. Combining physical training with transcranial direct current stimulation to improve gait in Parkinson's disease: a pilot randomized controlled study. Clin Rehabil. 2014;28(11):1115-1124.

20. Kaski D, Allum JH, Bronstein AM, Dominguez RO. Applying anodal tDCS during tango dancing in a patient with Parkinson's disease. Neurosci Lett. 2014;568:39-43.

21. Spagnolo F, Volonté MA, Fichera M, et al. Excitatory deep repetitive transcranial magnetic stimulation with $\mathrm{H}$-coil as add-on treatment of motor symptoms in Parkinson's disease: an open label, pilot study. Brain Stimul. 2014;7:297-300.

22. Fry FJ, Ades HW, Fry WJ. Production of reversible changes in the central nervous system by ultrasound. Science. 1958;127:83-84.

23. Huber PE, Rastert R, Simiantonakis I, et al. Magnetic resonance-guided therapy with focused ultrasound. Non-invasive surgery of breast carcinoma? Radiologe. 2001;41:173-180.

24. Schlesinger D, Benedict S, Diederich C, Gedroyc W, Klibanov A, Larner J. MR-guided focused ultrasound surgery, present and future. Med Phys. 2013;40:080901.

25. Dobrakowski PP, Machowska-Majchrzak AK, Labuz-Roszak B, Majchrzak KG, Kluczewska E, Pierzchała KB. MR-guided focused ultrasound: a new generation treatment of Parkinson's disease, essential tremor and neuropathic pain. Interv Neuroradiol. 2014;20:275-282.

26. Sturkenboom IH, Graff MJ, Hendriks JC, et al; OTiP Study Group. Efficacy of occupational therapy for patients with Parkinson's disease: a randomised controlled trial. Lancet Neurol. 2014;13:557-566.

27. Foster ER, Bedekar M, Tickle-Degnen L. Systematic review of the effectiveness of occupational therapy-related interventions for people with Parkinson's disease. Am J Occup Ther. 2014;68:39-49.

28. Thaut MH, McIntosh GC, Rice RR, Miller RA, Rathbun J, Brault JM. Rhythmic auditory stimulation in gait training for Parkinson's disease patients. Mov Disord. 1996;11(2):193-200.

29. Ellis T, de Goede CJ, Feldman RG, Wolters EC, Kwakkel G, Wagenaar RC. Efficacy of a physical therapy program in patients with Parkinson's disease: a randomized controlled trial. Arch Phys Med Rehabil. 2005;86: 626-632. 
30. Frazzitta G, Maestri R, Bertotti G, et al. Intensive rehabilitation treatment in early Parkinson's disease: a randomized pilot study with a 2-year follow-up. Neurorehabil Neural Repair. 2015;29(2):123-131.

31. Athukorala RP, Jones RD, Sella O, Huckabee ML. Skill training for swallowing rehabilitation in patients with Parkinson's disease. Arch Phys Med Rehabil. 2014;95:1374-1382.

32. Ploughman M, Shears J, Harris C, et al. Effectiveness of a novel community exercise transition program for people with moderate to severe neurological disabilities. NeuroRehabilitation. 2014;35(1):105-112.

33. Backlund EO, Granberg PO, Hamberger B, et al. Transplantation of adrenal medullary tissue to striatum in parkinsonism. First clinical trials. J Neurosurg. 1985;62:169-173.

34. Barker RA, Barrett J, Mason SL, Björklund A. Fetal dopaminergic transplantation trials and the future of neural grafting in Parkinson's disease. Lancet Neurol. 2013;12:84-91.

35. Dunnett SB. Neural tissue transplantation, repair, and rehabilitation. Handb Clin Neurol. 2013;110:43-59.

36. Parish CL, Thompson LH. Modulating Wnt signaling to improve cell replacement therapy for Parkinson's disease. J Mol Cell Biol. 2014;6: 54-63.

37. Thompson LH, Parish CL. Transplantation of fetal midbrain dopamine progenitors into a rodent model of Parkinson's disease. Methods Mol Biol. 2013;1059:169-180.

38. Freed CR, Greene PE, Breeze RE, et al. Transplantation of embryonic dopamine neurons for severe Parkinson's disease. $N$ Engl J Med. 2001;344:710-719.

39. Olanow CW, Goetz CG, Kordower JH, et al. A double-blind controlled trial of bilateral fetal nigral transplantation in Parkinson's disease. Ann Neurol. 2003;54(3):403-414.

40. Ma Y, Tang C, Chaly T, et al. Dopamine cell implantation in Parkinson's disease: long-term clinical and (18)F-FDOPA PET outcomes. $J$ Nucl Med. 2010;51(1):7-15.

41. Kefalopoulou Z, Politis M, Piccini P, et al. Long-term clinical outcome of fetal cell transplantation for Parkinson disease: two case reports. JAMA Neurol. 2014;71:83-87.

42. Nakao N, Kakishita K, Uematsu Y, et al. Enhancement of the response to levodopa therapy after intrastriatal transplantation of autologous sympathetic neurons in patients with Parkinson disease. $J$ Neurosurg. 2001;95:275-284.

43. Mínguez-Castellanos A, Escamilla-Sevilla F, Hotton GR, et al. Carotid body autotransplantation in Parkinson disease: a clinical and positron emission tomography study. $J$ Neurol Neurosurg Psychiatry. 2007;78(8):825-831.

44. Venkataramana NK, Kumar SK, Balaraju S, et al. Open-labeled study of unilateral autologous bone-marrow-derived mesenchymal stem cell transplantation in Parkinson's disease. Transl Res. 2010;155:62-70.

45. Venkataramana NK, Pal R, Rao SA, et al. Bilateral transplantation of allogenic adult human bone marrow-derived mesenchymal stem cells into the subventricular zone of Parkinson's disease: a pilot clinical study. Stem Cells Int. 2012;2012:931902.

46. Xue Y, Li X, Pang S, et al. Efficacy and safety of computer-assisted stereotactic transplantation of human retinal pigment epithelium cells in the treatment of Parkinson disease. J Comput Assist Tomogr. 2013;37: 333-337.

47. Yin F, Tian ZM, Liu S, et al. Transplantation of human retinal pigment epithelium cells in the treatment for Parkinson disease. CNS Neurosci Ther. 2012;18:1012-1020.

48. Watts RL, Raiser CD, Stover NP, et al. Stereotaxicintrastriatalimplanta tion of human retinal pigment epithelial (hRPE) cellsattached to gelatinmicrocarriers: a potential new cell therapy for Parkinson's disease. $J$ Neural Transm Suppl. 2003;65:215-227.

49. Gross RE, Watts RL, Hauser RA, et al; Spheramine Investigational Group. Intrastriatal transplantation of microcarrier-bound human retinal pigment epithelial cells versus sham surgery in patients with advanced Parkinson's disease: a double-blind, randomised, controlled trial. Lancet Neurol. 2011;10:509-519.
50. Hallett PJ, Cooper O, Sadi D, Robertson H, Mendez I, Isacson O. Longterm health of dopaminergic neuron transplants in Parkinson's disease patients. Cell Rep. 2014;7:1755-1761.

51. Bartus RT, Weinberg MS, Samulski RJ. Parkinson's disease gene therapy: success by design meets failure by efficacy. Mol Ther. 2014;22: 487-497.

52. Kaplitt MG, Feigin A, Tang C, et al. Safety and tolerability of gene therapy with an adeno-associated virus (AAV) borne GAD gene for Parkinson's disease: an open label, phase I trial. Lancet. 2007;369: 2097-2105

53. Eberling JL, Jagust WJ, Christine CW, et al. Results from a phase I safety trial of hAADC gene therapy for Parkinson disease. Neurology. 2008;70:1980-1983.

54. Marks WJ Jr, Ostrem JL, Verhagen L, et al. Safety and tolerability of intraputaminal delivery of CERE-120 (adeno-associated virus serotype 2-neurturin) to patients with idiopathic Parkinson's disease: an openlabel, phase I trial. Lancet Neurol. 2008;7(5):400-408.

55. Bartus RT, Baumann TL, Siffert J, et al. Safety/feasibility of targeting the substantia nigra with AAV2-neurturin in Parkinson patients. Neurology. 2013;80:1698-1701.

56. Perlow MJ, Freed WJ, Hoffer BJ, Seiger A, Olson L, Wyatt RJ. Brain grafts reduce motor abnormalities produced by destruction of nigrostriatal dopamine system. Science. 1979;204:643-647.

57. Rath A, Klein A, Papazoglou A, et al. Survival and functional restoration of human fetal ventral mesencephalon following transplantation in a rat model of Parkinson's disease. Cell Transplant. 2013;22:1281-1293.

58. Hansen JT, Bing GY, Notter MF, Gash DM. Paraneuronal grafts in unilateral 6-hydroxydopamine-lesioned rats: morphological aspects of adrenal chromaffin and carotid body glomus cell implants. Prog Brain Res. 1988;78:507-511.

59. Doudet DJ, Cornfeldt ML, Honey CR, Schweikert AW, Allen RC. PET imaging of implanted human retinal pigment epithelial cells in the MPTP-induced primate model of Parkinson's disease. Exp Neurol. 2004;189:361-368.

60. Schwarz EJ, Alexander GM, Prockop DJ, Azizi SA. Multipotential marrow stromal cells transduced to produce L-DOPA: engraftment in a rat model of Parkinson disease. Hum Gene Ther. 1999;10:2539-2549.

61. Wang Y, Yang J, Li H, et al. Hypoxia promotes dopaminergic differentiation of mesenchymal stem cells and shows benefits for transplantation in a rat model of Parkinson's disease. PLoS One. 2013;8:e54296.

62. Campeau L, Soler R, Sittadjody S, et al. Effects of allogeneic bone marrow derived mesenchymal stromal cell therapy on voiding function in a rat model of Parkinson disease. J Urol. 2014;191:850-859.

63. Soler R, Füllhase C, Hanson A, Campeau L, Santos C, Andersson KE. Stem cell therapy ameliorates bladder dysfunction in an animal model of Parkinson disease. J Urol. 2012;187:1491-1497.

64. Weiss ML, Medicetty S, Bledsoe AR, et al. Human umbilical cord matrix stem cells: preliminary characterization and effect of transplantation in a rodent model of Parkinson's disease. Stem Cells. 2006;24:781-792.

65. Xiong N, Cao X, Zhang Z, et al. Long-term efficacy and safety of human umbilical cord mesenchymal stromal cells in rotenone-induced hemiparkinsonian rats. Biol Blood Marrow Transplant. 2010;16: 1519-1529.

66. Mathieu P, Roca V, Gamba C, Del Pozo A, Pitossi F. Neuroprotective effects of human umbilical cord mesenchymal stromal cells in an immunocompetent animal model of Parkinson's disease. J Neuroimmunol. 2012;246:43-50.

67. Kang EJ, Lee YH, Kim MJ, et al. Transplantation of porcine umbilical cord matrix mesenchymal stem cells in a mouse model of Parkinson's disease. J Tissue Eng Regen Med. 2013;7:169-182.

68. Janowski M, Date I. Systemic neurotransplantation-a problem-oriented systematic review. Rev Neurosci. 2009;20:39-60.

69. Abo-Grisha N, Essawy S, Abo-Elmatty DM, Abdel-Hady Z. Effects of intravenous human umbilical cord blood CD34+ stem cell therapy versus levodopa in experimentally induced Parkinsonism in mice. Arch Med Sci. 2013;9:1138-1151. 
70. Arnhold S, Lenartz D, Kruttwig K, et al. Differentiation of green fluorescent protein-labeled embryonic stem cell-derived neural precursor cells into Thy-1-positive neurons and glia after transplantation into adult rat striatum. J Neurosurg. 2000;93:1026-1032.

71. Bjorklund LM, Sánchez-Pernaute R, Chung S, et al. Embryonic stem cells develop into functional dopaminergic neurons after transplantation in a Parkinson rat model. Proc Natl Acad Sci U S A. 2002;99: 2344-2349.

72. Ziavra D, Makri G, Giompres P, et al. Neural stem cells transplanted in a mouse model of Parkinson's disease differentiate to neuronal phenotypes and reduce rotational deficit. CNS Neurol Disord Drug Targets. 2012;11:829-835.

73. Proschel C, Stripay JL, Shih CH, Munger JC, Noble MD. Delayed transplantation of precursor cell-derived astrocytes provides multiple benefits in a rat model of Parkinsons. EMBO Mol Med. 2014;6:504-518.

74. Agrawal AK, Shukla S, Chaturvedi RK, et al. Olfactory ensheathing cell transplantation restores functional deficits in rat model of Parkinson's disease: a cotransplantation approach with fetal ventral mesencephalic cells. Neurobiol Dis. 2004;16:516-526.

75. Johansson S, Lee IH, Olson L, Spenger C. Olfactory ensheathing glial co-grafts improve functional recovery in rats with 6-OHDA lesions. Brain. 2005;128:2961-2976.

76. Shukla S, Chaturvedi RK, Seth K, Roy NS, Agrawal AK. Enhanced survival and function of neural stem cells-derived dopaminergic neurons under influence of olfactory ensheathing cells in parkinsonianrats. J Neurochem. 2009;109:436-451.

77. Feng L, Meng H, Wu F, et al. Olfactory ensheathing cells conditioned medium prevented apoptosis induced by 6-OHDA in PC12 cells through modulation of intrinsic apoptotic pathways. Int J Dev Neurosci. 2008;26:323-329.
78. Meissner W, Harnack D, Paul G, et al. Deep brain stimulation of subthalamic neurons increases striatal dopamine metabolism and induces contralateral circling in freely moving 6-hydroxydopamine-lesioned rats. Neurosci Lett. 2002;328:105-108.

79. Meissner W, Reum T, Paul G, et al. Striatal dopaminergic metabolism is increased by deep brain stimulation of the subthalamic nucleus in 6-hydroxydopamine lesioned rats. Neurosci Lett. 2001;303: $165-168$.

80. Lortet S, Lacombe E, Boulanger N, et al. Striatal molecular signature of subchronic subthalamic nucleus high frequency stimulation in parkinsonian rat. PLoS One. 2013;8:e60447.

81. Al-Jarrah M, Jamous M, Al Zailaey K, Bweir SO. Endurance exercise training promotes angiogenesis in the brain of chronic/progressive mouse model of Parkinson's disease. NeuroRehabilitation. 2010;26 369-373.

82. Al-Jarrah M, Jamous M. Effect of endurance exercise training on the expression of GFAP, S100B, and NSE in the striatum of chronic/ progressive mouse model of Parkinson's disease. NeuroRehabilitation. 2011;28:359-363.

83. A1-Jarrah M, Obaidat H, Bataineh Z, Walton L, Al-Khateeb A. Endurance exercise training protects against the upregulation of nitric oxide in the striatum of MPTP/probenecid mouse model of Parkinson's disease. NeuroRehabilitation. 2013;32:141-147.

84. Wang Z, Myers KG, Guo Y, et al. Functional reorganization of motor and limbic circuits after exercise training in a rat model of bilateral parkinsonism. PLoS One. 2013;8:e80058.

85. Zhao L, He LX, Huang SN, et al. Protection of vibration training on dopamine neurons and up-regulation of brain-derived neurotrophic factor in a MPTP mouse model of Parkinson's disease. Physiol Res. 2014;63:649-657.
Journal of Neurorestoratology

\section{Publish your work in this journal}

The Journal of Neurorestoratology is an international, peer-reviewed, open access online journal publishing original research and review articles on the subject of Neurorestoratology. To provide complete coverage of this revolutionary field the Journal of Neurorestoratology will report on relevant experimental research, technological advances, and

\section{Dovepress}

clinical achievements. The manuscript management system is completely online and includes a very quick and fair peer-review system, which is all easy to use. Visit http://www.dovepress.com/testimonials.php to read real quotes from published authors.

Submit your manuscript here: http://www.dovepress.com/journal-of-neurorestoratology-journal 